\title{
La noopolítica como mediación en el ánalisis de las competencias ciudadanas ${ }^{1}$
}

\section{Non-politics as mediation in the analysis of citizen's competences}

Recibido: 23 de abril de 2015 - Revisado: 23 de octubre de 2015 - Aceptado: 06 de abril de 2016.

\author{
Gustavo Octavio García Rodríguez ${ }^{2}$ \\ Chris Aleydi González H. ${ }^{3}$ \\ Dory Luz González Hernández ${ }^{4}$ \\ Jenny Alexandra Jiménez Medina ${ }^{5}$
}

\begin{abstract}
Resumen
Este artículo presenta los resultados de una investigación fundamentada en la categoría de noopolítica, para analizar los procesos de ciudadanización de los estudiantes de la Fundación Universitaria Los Libertadores, producidos en el contexto de las prácticas discursivas, las apropiaciones y usos de la red social Facebook en la comprensión de nuevas subjetividades consideradas desde dicha categoría, ella entendida como el dominio y el ejercicio del poder sobre la conciencia misma de los sujetos, a través de los consumos de información posibilitados por los mass media. En la primera parte de este texto, se aproxima a las discusiones sobre los conceptos de ciudadanía, redes sociales y noopolítica. En la segunda parte, se expone las consideraciones metodológicas enfocadas en la etnografía virtual. Al final, se ofrecen los resultados y la discusión sobre estos procesos de ciudadanización.
\end{abstract}

\section{Palabras clave}

Ciudadanía, competencias ciudadanas, noopolítica, redes sociales virtuales.

\begin{abstract}
This article presents the results of a research based on the category of noopolitics, to analyze the processes of citizenship of students of the Fundación Universitaria Los Libertadores, produced in the context of discursive practices, appropriations and uses of the social network Facebook in The understanding of new subjectivities considered from this category, understood as the domination and exercise of power over the consciousness of the subjects themselves, through the consumption of information made possible by the mass media. The first part of this text approaches debates about the concepts of citizenship, social networks and noo-politics. In the second part, we present methodological considerations focused on virtual ethnography. In the end, the results and the discussion on these processes of citizenship are offered.
\end{abstract}

\section{Keywords}

Citizenship, citizen competences, noo-politics, virtual social networks.

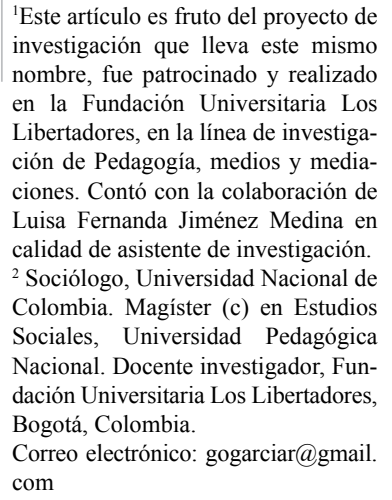

${ }^{1}$ Este artículo es fruto del proyecto de investigación que lleva este mismo nombre, fue patrocinado y realizado en la Fundación Universitaria Los Libertadores, en la línea de investigación de Pedagogía, medios y mediaciones. Contó con la colaboración de Luisa Fernanda Jiménez Medina en calidad de asistente de investigación. ${ }^{2}$ Sociólogo, Universidad Nacional de Colombia. Magíster (c) en Estudios Sociales, Universidad Pedagógica Nacional. Docente investigador, Fundación Universitaria Los Libertadores, Bogotá, Colombia.

Correo electrónico: gogarciar@gmail. com

${ }^{3}$ Lingüista, Universidad Nacional de Colombia. Magíster en Investigación Social Interdisciplinaria, Universidad Distrital Francisco José de Caldas. Docente investigadora, Fundación Universitaria Los Libertadores, Bogotá, Colombia.

Correo electrónico: cagonzalezhe@ gmail.com

${ }^{4}$ Licenciada en Ciencias Sociales, Universidad Francisco José de Caldas. Especialista en Pedagogía Audiovisual, Universidad El Bosque. Magíster en Investigación Social Interdisciplinaria, Universidad Francisco José de Caldas. Doctora (c) en Estudios Sociales de América Latina, Universidad Nacional de Córdoba. Docente-investigadora, Corporación Universitaria Republicana y Universidad Libre de Colombia, Bogotá, Colombia.

Correo electrónico: doryluz.gonzalez@yahoo.com

${ }^{5}$ Filósofa, Universidad Nacional de Colombia, Magíster en investigación Social Interdisciplinaria, Universidad Distrital Francisco José de Caldas, Doctora (c) en Estudios Sociales de América Latina, Universidad Nacional de Córdoba. Docente Investigadora, Universidad Autónoma de Colombia, Bogotá, Colombia.

Correo electrónico: jjimenez.medina@fuac.edu.co

Para citar este artículo use: García, G., González, C., González, D., \& Jiménez, J. (2017). La noopolítica como mediación en el análisis de las competencias ciudadanas. Civilizar Ciencias Sociales y Humanas, 17(32), 171-196. Doi: $10.22518 / 16578953.825$ 


\section{Introducción}

Actualmente, en la mayoría de Instituciones de Educación Superior existe una latente preocupación por los desempeños de los estudiantes en la evaluación de carácter estatal que realiza el Instituto Colombiano para la Evaluación de la Educación (ICFES) ${ }^{1}$ al finalizar los procesos académicos pregraduales. Esta prueba mide la calidad de los procesos educativos y formación profesional, a través de una evaluación por competencias -de acuerdo con la "política de competencias" establecida por el Ministerio de Educación Nacional-, fundamentales en la constitución del saber, hacer y ser en el profesional.

Las competencias que arrojan resultados más deficientes son las organizadas en el módulo "genérico", presentado por estudiantes de cualquier programa, ya sea a nivel técnico, tecnológico o profesional; evidenciando serios problemas en escritura, lectura, razonamiento lógico, adquisición de la segunda lengua y ciudadanía de los futuros egresados, estos resultados se pueden apreciar en la página web del ICFES y otras entidades que realizan análisis en relación con esta temática.

Respecto a la evaluación en ciudadanía, hay sobre la mesa muchas discusiones, pues si bien, los conocimientos de "ciudadanía" por parte de los estudiantes no son evidentes desde una mirada teórico-conceptual, en la práctica se puede encontrar lo contrario.

Así, lo anterior muestra un enorme vacío contextual, pues la ciudadanía es un concepto connotativo que continuamente se transforma, por un lado; y por otro, los estudiantes no dimensionan el verdadero significado de la prueba y lo limitan a la interpretación de ser "cívico" o de los componentes cognitivos de una evaluación.

El modelo de evaluación que propone el ICFES basado en las políticas educativas nacionales, se sustenta en las denominadas competencias: "un saber-hacer flexible que se lleva a cabo en distintos contextos, incluyendo situaciones distintas de aquellas en las que se aprendieron" (Rodríguez, Ruiz, \& Guerra, 2007, p. 147). Dichas competencias son las que miden cómo se constituye un ciudadano competente egresado de la educación superior.

Las competencias ciudadanas son en la actualidad un tema de particular relevancia en el entorno educativo, así como en el político; su papel, objetivos, enfoques y perspectivas, están a plena luz de la discusión académica por lo interesante de su propuesta, así como por los claros-oscuros que ella puede llegar a contener. Dichas competencias cobran aún más relevancia si se tiene en cuenta lo particular de la sociedad colombiana en medio de la cual pretenden materializarse, pues parece que la disposición en la que se realiza la evaluación se desdibuja de la realidad en la que están inmersos los sujetos y se ata la competencia con la habilidad, perdiendo completamente la mirada sociológica y simbólica.

Esta investigación ha partido, entre otros, del hecho según el cual es necesario revisar críticamente la propuesta de la formación que proponen las competencias ciudadanas, en específico, desde el panorama que provee el concepto de ciudadanía, así como inquirir sobre los nuevos mecanismos de interacción de los jóvenes que residen en la virtualidad de las redes sociales, haciendo uso de nuevos lenguajes y apropiándose mediáticamente de iniciativas políticas, sociales y culturales.

Con lo anterior, en la investigación se identifican dos grandes perspectivas: la primera, la noción de ciudadanía y competencia ciudadana y, la segunda, los escenarios actuales de interacción mediáticos donde tiene lugar las prácticas y sensibilidades de los estudiantes universitarios, particularmente los de La Fundación Universitaria Los Libertadores. La articulación de estos ejes se realiza a través de las 
nuevas relaciones de poder manifestadas en la tecnificación.

Algunos interrogantes que dieron soporte a los elementos anteriores fueron: ¿qué tipo de ciudadanía están evaluando estas pruebas? ¿Cómo evaluar una noción que se encuentra en constante definición? ¿Cómo se construye la ciudadanía contemporánea?

En el contexto real, los individuos no pueden ser observados actualmente con dichas estructuras, teniendo en cuenta que los espacios en los que se están construyendo a sí mismos y en los que residen gran parte de su tiempo existencial son las redes sociales. Estas se han encargado de propiciar nuevos mecanismos de interacción, donde los interlocutores utilizan formas no convencionales de expresión. En esta perspectiva, las competencias deben reorientarse y ampliarse a estos medios que han cambiado la forma de establecer relaciones interculturales, pues son ellas las que dominan en la actualidad, la validez o la existencia de un individuo. Las competencias ciudadanas deben entonces actualizarse en la medida en que las necesidades del individuo se van transformando.

La pregunta de investigación que ha definido y propuesto la ruta de esta pesquisa ha sido la siguiente: ¿cómo la noopolítica contribuye al análisis de los procesos de ciudadanización en sujetos contemporáneos - estudiantes de la Fundación Universitaria Los Libertadores- para un nuevo diagnóstico de las competencias ciudadanas?

\section{Ciudadanía y competencias ciuda- danas.}

La primera de estas categorías, la ciudadanía, debe verse como un proceso de producción de subjetividades ${ }^{2}$, de confluencia de diversos universos simbólicos, donde las interacciones sociales producen significados enmarcados en determinados contextos, debido a que las co- munidades y sus actores sociales construyen sus particulares prácticas interpretativas.

Para este proyecto analizar las competencias ciudadanas ajustadas a estos nuevos contextos es pertinente, pues es allí donde se tejen las discusiones, las reflexiones, las críticas frente a las problemáticas sociales actuales. El rol del nuevo sujeto debe comprenderse, así como las nuevas perspectivas de ciudadanía y los ejercicios de subjetivación que se construyen en el espacio virtual.

Tal y como lo señalan Mejía y Perafán (2006), es necesario "contribuir a la discusión sobre lo que significa e implica la adopción de ciertas nociones de ciudadanía y de una educación para la ciudadanía" (p. 23). Convergemos a este respecto con la postura de Rodríguez, Ruiz y Guerra (2007) en tanto que "más que tener una cátedra de cívica, es importante generar un espacio de reflexión dentro de las aulas en el que se fomente el desarrollo de las competencias ciudadanas" (p. 140). Así, lo anterior ha sido un eje principal para el abordaje de este ejercicio, una iniciativa guiada por una suerte de interés emancipatorio- cognoscitivo ${ }^{3}$.

Se busca entonces que, mediante las competencias ciudadanas, el ciudadano pueda incidir activamente en tres campos vitales para la convivencia social: la resignificación del sentido de la política, la renovación de criterios de legitimación de lo público y el fortalecimiento de una cultura de la civilidad (Delgado, 2003).

Las competencias ciudadanas tal y como son expuestas por el Ministerio de Educación Nacional, corresponden más a una propuesta de formación en civismo y democracia que con la formación de un ciudadano o ciudadana propiamente dicho. De una forma sintetizada puede verse a las competencias como un conjunto de conocimientos, actitudes y habilidades (cognitivas, emocionales y comunicativas) que buscan que el ciudadano democrático que se 
está formando "esté dispuesto a actuar y actúe de manera constructiva y justa en la sociedad" (Rodríguez et al., 2007, p. 147).

En términos sencillos y como referente inicial, puede pensarse que la ciudadanía es un concepto ambiguo, en construcción constante, que se ha debatido entre las lógicas de la inclusión y exclusión social; en él, la puesta en juego es más que afirmar o titular a ciertas personas o grupos con un conglomerado de derechos, como esa "concesión, como algo a lo que se está o no en derecho de recibir por el poder soberano del Estado" (Svransky, 2011, p. 114), se manifiesta también como "límite, frontera para excluir a otros” (Del Re, 2001, p. 189).

Es por lo anterior, que se ha hecho imperativo reflexionar sobre el ciudadano, pues hoy rompe el paradigma tradicional, su actuar político cobra nuevos escenarios donde se evidencia su práctica ciudadana dignificante y visibilizadora de los excluidos, que a la vez se configura como la oposición al modelo económico globalizado. Así, otro cuestionamiento que surge: ¿es suficiente con una ciudadanía sustantiva reconocerse como ciudadano dejando de lado las dinámicas sociales, económicas y culturales que sustentan la ciudadanía contemporánea? La ciudadanía como concepto y como ejercicio político propiamente dicho, comprende un universo muy vasto que amerita ser contemplado con la complejidad que lo merece; esto con mayor énfasis si estamos pensando en estudiantes universitarios, en su formación ciudadana.

Los referentes teórico-conceptuales tomados para profundizar en el concepto de ciudadanía se organizaron en tres grandes momentos, el primero, correspondiente a lo que se ha denominado pensamiento clásico; el segundo, en el que se situaron tres modelos de sociedad: liberal, republicana y comunitarista; el tercero, denominado la ciudadanía hoy.

El momento relacionado con el pensamiento clásico y la ciudadanía, tuvo en cuenta el caso griego (Aristóteles y Pericles) y romano (Cayo y Mario); luego, el Medioevo y la ciudadanía, en particular el proceso de formación de las ciudades Estado y, finalmente, el siglo XVIII y el discurso de los derechos.

El segundo momento destacó las ideas de Jhon Rawls ligadas al liberalismo, las de Charles Taylor y Adela Cortina enmarcadas dentro del republicanismo y las de Michael Walzer y Jürgen Habermas en el caso del comunitarismo; destáquese que no se han expuesto como formas puras que encarna una concepción liberal, republicana o comunitaria de la ciudadanía, ya que es ampliamente conocido que, por ejemplo Michael Walzer deambuló de las perspectivas liberales a las comunitarias así como Jürgen Habermas del comunitarismo a la ciudadanía postnacional.

El tercer momento, acuñado como la ciudadanía hoy, destacó las siguientes perspectivas: la ciudadanía diferenciada (Iris Young y Carole Pateman), multicultural (Will Kymlicka), postnacional (Jürgen Habermas), el cosmopolitismo cívico (David Held, Martha Nussbaum, Adela Cortina), la propuesta de la ciudadanía extensa (Fernando Calderón, Martín Hopenhayn y Ernesto Ottone), ciudadanía desde abajo (Elizabeth Jelin), la ciudadanía ambiental-global y, finalmente, la digital.

\section{Las redes sociales virtuales como nuevos escenarios de participación.}

La segunda perspectiva, son los nuevos escenarios de participación, aquí la referencia se da a la vinculación de los sujetos a la web $2.0^{4}$. Esta virtualidad brinda nuevas formas de apropiación de la información, de hacerse sujetos, de condicionar actuares, pues si bien parece que el sujeto es libre de transitar, es un sujeto consumidor de contenidos, de iconos, de imágenes, que le permiten crearse un rol de relevancia y de reconocimiento en este espacio potencial.

Las tecnologías de la información y la comunicación son productos de consumo que 
tienen un valor simbólico en los contextos culturales y sociales, pues se asocian a prácticas significativas de representación y de reproducción de las ciudadanías. Pero no solo se deben entender como objetos de consumo, sino como herramientas de producción y difusión de objetos digitales (fotografías, videos, imágenes, memes, entre otros), proclives a ser consumibles.

Internet, según Ardèvol, Estalella y Domínguez (2008), ha permitido la aparición de comunidades virtuales, objeto de estudio hoy de las y los científicos sociales, pero no solo posee está dimensión, sino internet también se convierte en un instrumento de la práctica científica. En concordancia, internet no solo es el objeto de estudio, sino también es el instrumento de recolección de información, presenta una doble partida que es mucho más provechosa para los investigadores sociales.

La comunicación en este nuevo escenario cobra otro sentido, "el poder de la palabra"; la trasmisión de opiniones la convierte en un recio instrumento social.Los movimientos ciudadanos ahora se gestan a través de estas redes sociales, pues su proximidad y accesibilidad tienen una repercusión sustancial en la construcción del individuo y la colectividad.

Estas nuevas dinámicas en la esfera virtual, vislumbran a un sujeto mediatizado, consumista, en medio de flujos de información y comunicación. Un sujeto que se encuentra inmerso en las prácticas actuales de la sociedad de apropiación y uso de productos que poseen un valor simbólico. Un consumo que le permite al sujeto diferenciación social, exclusión, integración, comunicación, tener una distinción simbólica con respecto a los otros. El consumo de los jóvenes en la contemporaneidad permite el surgimiento de nuevos espacios de consumo, la conformación de nuevos grupos, como sucede en las redes sociales virtuales, donde ellos adquieren y usan nuevos productos que les permiten tener una distinción y reconocimiento frente a los otros.
Un espacio virtual, donde las relaciones de poder en las sociedades de control se reconfiguran, un poder a distancia que guía las conductas de los individuos y que puede ser evidente en los nuevos dispositivos que son consumidos por los jóvenes. Lo anterior se puede llamar, según Maurizzio Lazzarato, noopolítica.

\section{El concepto de noopolítica.}

Tiene implicación directa con una nueva modalidad de ejercicio del poder, mediante una distinción entre el bios, como control del cuerpo y el bios, como control de la memoria. En este plano, se encuentran los audiovisuales, internet, la constitución de la opinión pública, las representaciones, en otras palabras, el control de los públicos ${ }^{5}$.

Dicha noción concierne entonces a la forma en que se encuentran organizadas las sociedades de control, en la medida en que juega la tecnología y la información en las relaciones humanas, de ahí lo fundamental de estas nuevas máquinas de expresión del capitalismo.

En ese orden de ideas Lazzarato (2006a) entiende a la noopolítica como la nueva manifestación de la sociedad de control en la que se orienta el dominio y el ejercicio del poder sobre la conciencia misma de los sujetos por medio de los consumos culturales como escenario de sujeción, en el que se suscriben los procesos de ciudadanización contemporáneos a través del consumo de la información, por parte de las y los jóvenes, de los mass media y las pantallas en red de la informática. La noopolítica (de noos alma en sentido aristotélico y política, poder), una estrategia de control en sí misma es definida complementariamente como:

Las técnicas de control que se ejerce sobre el cerebro, implicando en principio la atención, para controlar la memoria y su potencia virtual. La modulación de la memoria sería entonces la función más importante de la noopolítica. Si las disciplinas moldeaban los cuer- 
pos constituyendo hábitos principalmente en la memoria corporal, las sociedades de control modulan los cerebros y constituyen hábitos principalmente en la memoria espiritual (Lazzarato, 2006a, p. 100).

La noopolítica actúa a un nivel desterritorializado, desde el cual dirige y organiza las relaciones de poder, siendo su dispositivo principal el noopoder. En primera instancia, los dispositivos de modulación de la noopolítica serán las tecnologías de acción a distancia, aprovechando las técnicas del contagio que propician "los públicos"; esto es, la comunidad de consumidores que comparten creencias, voluntades y que (a pesar de la diversidad de discurso explícitos o tácitos y la heterogeneidad) se unifican en lo que en términos deleuzeanos sería el ritornelo, o el sentimiento de unicidad y completud. En segundo lugar, la gobernabilidad en la contemporaneidad la ejercen mecanismos noopolíticos, es decir, la captura de los deseos, la memoria, las creencias y la producción de miedos dependerá de la maquinaria empresarial.

Contando ya con algunas claridades en el nivel teórico-conceptual, se pasará a presentar los principales elementos y procesos llevados a cabo en la operacionalización metodológica de dichos conceptos.

\section{Consideraciones metodológicas}

En esta investigación se ha llevado a cabo un proceso metodológico que buscó articular las perspectivas cualitativas y cuantitativas, una metodología mixta de investigación que pretendió no solo triangular información, sino complementar las perspectivas sobre el problema analizado para lograr una mirada más compleja sobre el mismo. Si bien ha tenido mayor protagonismo lo cualitativo, se ha logrado llevar a cabo un ejercicio complementario que ha dado una mayor amplitud de referentes analíticos. Acorde con Bonilla y Rodríguez (2000), esta vía ha permitido "fortalecer el proceso de generar conocimiento de la realidad social" (p. 103).
Los instrumentos implementados fueron: etnografía virtual, debates y encuestas. El método aplicado al análisis de los instrumentos se orientó por la perspectiva hermenéutica y comprensiva, particularmente, en los casos de etnografía virtual y debates; para el caso de las encuestas se apeló al análisis descriptivo. Así mismo, esta indagación operó teniendo por objetivo alcanzar el nivel descriptivo en cada uno de los temas y ejes que fueron inquiridos, y tuvo por población a los estudiantes de la Fundación Universitaria Los Libertadores.

La etnografía virtual, cuyas generalidades se señalan más adelante, tuvo como objetivo identificar la forma en que las y los estudiantes de la Fundación Universitaria Los Libertadores asumieron -en tanto ciudadanos- la coyuntura política y social experimentada en la ciudad de Bogotá (Colombia) alrededor del "paro agrariocampesino" los días 29, 30 y 31 de agosto del año $2013^{6}$. Esta técnica de investigación apeló a la red social Facebook cuyos partícipes han sido estudiantes de la universidad; su diseño y aplicación se llevó a cabo en los meses de septiembre y octubre del año 2013.

La etnografía se llevó a cabo en tres aplicativos de grupos conformados en Facebook en los que se encuentran vinculados estudiantes de la Fundación Universitaria Los Libertadores. La naturaleza de estos grupos, en lo fundamental, es de libre acceso, se permite conocer los posicionamientos de estudiantes de la fundación, pero sin tener claridades respecto a quiénes son, programa en el que se encuentran inscritos o inscritas, semestre que cursan, o jornadas diurna o nocturna?

Los grupos se analizaron los días 29, 30 y 31 de agosto, fechas en las cuales el "paro agrario/campesino" realizado en Colombia se manifestó con más fuerza en la ciudad de Bogotá D. C., convirtiéndose en el principal objeto de discusión en esta red social.

Se juzgó relevante aprovechar esta coyuntura nacional pues permitió revisar el ejer- 
cicio de los estudiantes en tanto ciudadanos, frente a una problemática real y concreta de incidencia en diferentes ámbitos. Se evitó así trabajar sobre elementos abstractos o discursivos relacionados con la ciudadanía, posibilitando un acercamiento más pragmático a ese tipo de realidades.

Los grupos sometidos a revisión etnográfica fueron los siguientes:

a. Memes U Libertadores (http://www. facebook.com $/$ memesulibertadores? fref $=$ ts \&fi lter $=1$ )

b. Página oficial en Facebook de la Fundación Universitaria Los Libertadores (http:// www.facebook.com/pages/Fundación-Universitaria-Los-Libertadores-Página-Oficial/11303 5982110296? fref $=$ ts)

c. Confesiones Universidad Los Libertadores (https://www.facebook.com/ConfesionesUlibertadores/posts/347928925341403)

En ese sentido, lo que se intentó identificar en un primer momento fue la praxis ciudadana evaluada bajo los siguientes ejes:

a. Pertinencia y solidez de los enunciados respecto de una situación problema.

b. Perspectivas sobre una situación problema.

c. Análisis de situaciones o problemas.

Estos elementos se extrajeron y unificaron para acercarse a las siguientes dimensiones que hacen parte del módulo de competencias ciudadanas que se evalúa mediante la prueba Saber Pro: analizar y evaluar la pertinencia y solidez de enunciados; reconocer, contrastar y valorar distintas perspectivas; comprender que los problemas o fenómenos sociales y sus soluciones son multidimensionales y reconocer interacciones entre estas dimensiones.
La etnografía virtual posibilitó acceder a lo que las y los estudiantes manifiestan por medio del texto escrito o a través de un gráfico, en medio de las posibilidades (accesibilidad, tiempo real, rapidez del flujo de información, entre otros) y limitaciones (anonimato de las personas, posibilidad de eliminar o manipular comentarios y afirmaciones luego de haber sido recuperadas, brevedad de los planteamientos y comentarios, poca rigurosidad lingüística y expositiva de los mismos, entre otras) que posee una red social como lo es Facebook (la más grande de todas las redes sociales existentes en la actualidad desde su fundación en 2006 y que opera en español desde el año 2007). A este respecto, vale la pena resaltar que acorde el grupo cobra mayor oficialidad se tiende a modular las expresiones y a hacer uso de un lenguaje más formal por parte de quienes intervienen en las discusiones o lo que se denomina como conversaciones.

La etnografía permite describir de una manera densa y compleja las múltiples relaciones presentes en la contemporaneidad, permitiendo vislumbrar las diversas caras de los sujetos investigados, pues no solo le interesa la interacción verbal, sino la kinésica y prosémica, así como las influencias del entorno al trasmitir sus representaciones e identidades.

Una etnografía virtual puede observar en detalle los usos de esas nuevas tecnologías, como lo dice Hine (2004): "consiste en que un investigador se sumerja en el mundo que estudia por un tiempo determinado y tome en cuenta las relaciones, actividades y significaciones que se forjan entre quienes participan en los procesos sociales de ese mundo" (p. 82).

La etnografía virtual se desarrolló con el objetivo de estudiar no solo los usos, sino también las prácticas y cómo estas prácticas cobran una significancia para los sujetos, adicional tiene dos miradas, la tecnología como texto donde el análisis discursivo cobra importancia para observar las caracterizaciones de los relatos y 
las interacciones, que permiten ver la correspondencia del uso en la situación (Hine, 2004).

Para Hine (2004), la etnografía virtual permite comprender que el agente de cambio no es la tecnología en sí misma, sino los usos de esta, las construcciones de sentido que se configuran alrededor de ella, por eso Facebook se constituye como el ideal etnográfico virtual, por las múltiples formas de participación.

Facebook es considerada la red de redes pues participan e interactúan personas con intereses comunes que generalmente se concretizan en la publicación de contenidos. Los vínculos que se tejen en ella son de diversa índole, pues se pueden encontrar relaciones de amistad, amor, académicas, profesionales y en los últimos años la inclusión mercadotécnica, pues en ella se realiza un merchandising de negocios particulares que han logrado un éxito mediano.

Uno de los ejes fue observar las prácticas comunicativas o narrativas de los estudiantes en este espacio virtual, pues allí, se consiente la alteridad, se reconfiguran las relaciones y se logran mutar las subjetividades de los usuarios.

Por su lado, los debates se consolidaron bajo la premisa de establecer las posibles distinciones entre la ciudadanía problematizada como una cuestión formal, pasiva, individualista, cercana al civismo, frente a una concepción de la ciudadanía que se sitúa como ejercicio activo, fundamentado, libre y preocupado por el bienestar general. Así mismo, se pudo discutir desde la perspectiva profesional de las y los estudiantes como ciudadanas y ciudadanos, las situaciones presentadas en algunos videos, que fueron presentados antes del debate, indagando el rol del ciudadano que ellos y ellas plantean y asumen en la realidad.

Un debate permite reunir un grupo de personas con un interés en común que aportan al desarrollo de un tema en específico, la ventaja de un debate es que se puede reunir mayor información de lo normal, pues cada miembro en la reunión está dispuesto a brindar información de forma abierta y libre.

En los debates realizados en la Fundación Universitaria Los Libertadores se pudo contar con una participación alta de estudiantes y la presencia de educandos de todos los programas y semestres.

Las discusiones se condujeron a través de algunos documentales, donde las y los estudiantes a través de los elementos hallados, podían discutir y enlazar con lo que ellos y ellas consideran ciudadanía. El diálogo entre los estudiantes y el moderador (miembro del equipo de investigación) permitió preguntar, responder, comentar y discutir, pues la flexibilidad condescendió explorar otros temas relacionados que surgieron en la charla.

Este tipo de ejercicios asintieron la comunicación colaborativa y la participación efectiva. Para los ejercicios, se observó el interés en las temáticas, la atención de los estudiantes $\mathrm{y}$ una participación total de todos los miembros del grupo. Por ejemplo, uno de los debates se centró en el tema de los desaparecidos a través del documental "Cuántos son los desaparecidos en el país" (Morris, 2010) ${ }^{8}$, y en preguntas sobre participación ciudadana que buscaban averiguar sobre las formas de participación ciudadana de estos jóvenes. El otro de los debates trató el tema de la pobreza con el documental "La isla de las flores" (Furtado, 1989) ${ }^{9}$ y la noción de ciudadanía, que buscaba indagar sobre lo que las y los estudiantes interpretaban como ciudadanía.

Así, se encontró que las temáticas expuestas fueron desconcertantes pues algunos desconocían esa realidad; para otros fue más un tema del diario vivir; en cuanto a la ciudadanía la semejaron al civismo y a los valores, y la participación ciudadana fue para ellas y ellos más dependiente de elementos externos. 
Las encuestas se centraron en reconocer la forma en que las y los estudiantes asumen componentes centrales de la democracia, el gobierno y la ciudadanía, tales como la Constitución Política, la constitución y ejercicio del Estado, el modelo democrático de gobierno, los derechos y deberes, la relación ciudadanía-globalizaciónmedios de comunicación, entre otros.

Lo anterior enfocado a tres elementos que hacen parte de las denominadas competencias ciudadanas:

a. Comprender qué es la Constitución Política de Colombia y sus fundamentos.

b. Conocer los derechos y deberes que la Constitución consagra.

c. Conocer la organización del Estado de acuerdo con la Constitución.

La encuesta provee un volumen mucho mayor de información, ha posibilitado conjurar varias de las percepciones que los y las estudiantes tienen frente a los temas ya señalados, contando con la posibilidad de destacar ciertas tendencias generales que se han encontrado.

\section{Resultados}

\section{Debate.}

Es evidente que los estudiantes de la Fundación Universitaria Los Libertadores poseen una somera conciencia política y por ende una superficial conciencia ciudadana, tal vez no manifiesta frente a los ejercicios normativos-cognitivos de derechos y deberes; es tan manifiesta este tipo de ciudadanía, que a través de la conversación se dibujaron rasgos de ciudadanías comunitarias, liberales, republicanas, cosmopolitas, digitales, sin tener la plena conciencia de la teorización de estas.

"El Estado también limita mucho eso de conocer nuestros deberes y derechos, porque uno dice: -Tengo derecho a una vivienda, pero cómo la consigo-, entonces prefiero vivir en la calle, tengo derecho a una educación, pero no puedo, pues son muchas bibliotecas públicas que limitan la entrada, dicen: -No, usted viene vestido así [...] porque usted va a venir es acá a dañar los libros-, o sea, si como que ya encasillan a la persona de una forma y le limitan sus propios derechos, entonces ellos dicen -para qué tengo este derecho si no lo voy a hacer cumplir ni puedo hacerlo cumplir-" (Estudiante, sexto semestre, comunicación personal, octubre de 2014)

Sus ejercicios ciudadanos son más pasivos, pues el desencanto por la institución, por los mecanismos de participación y elección popular en un país democrático son evidentes, a pesar de ello hay punto de fuga, hay un interés por las problemáticas sociales, un reconocimiento de los derechos colectivos e individuales que se manifiesta a través de los modos de subjetivación presentes y evidentes en el diálogo, así como los ejercicios de una participación política diferenciada sin representación y mediática.

Por otro lado, en algunos casos ese interés era mucho más emotivo sin ningún tipo de compromiso, ya que para ellos hay siempre algo que lo imposibilita. Es preocupante, que en los dos debates aparece el miedo como detención en el momento de ejercer una vía de hecho, lo que evidencia que por parte de mecanismos externos se ha ejercido un control y dominio sobre el cuerpo y mente de estos jóvenes.

Adicional, la representación que se tiene del Estado y sus miembros e incluso del mismo gobierno, es bastante negativa, en algunos casos se culpa al poder que se tiene y como se ejerce este.

"Mi hermano trabaja en algo de Bogotá Humana y eso es una cadena de corrupción y de robos y de engaños, y si tú eres mi primo o tú eres mi familiar y yo te dejo pasar para que te den más rápido todo, entonces no es solo dar y 
dar, sino lo que ha hecho el alcalde o alcaldes que han montado planes que para que la gente sea más humana, que conciencia ciudadana, que no sé qué, pero es que aquí hace falta no sé, algo más fuerte porque es que ya ni por educación, ni por ayudas ha funcionado" (Estudiante, octavo semestre, comunicación personal, octubre de 2014).

Así con todo esto, parece que los estudiantes tomaran una posición de espectadores frente a las diferentes problemáticas sociales, económicas y políticas que afectan su entorno. $\mathrm{Su}$ accionar depende del grado de pertenencia a su esfera privada, es decir, si un hecho afecta de manera cercana al sujeto o a su familia, este siente que debe participar políticamente, de lo contrario no. En relación con el contenido de los documentales, algunos estudiantes manifestaron que al no tener un capital econó- mico no se puede exigir o tener algún tipo de derecho.

Continuando, se considera por parte de los estudiantes de la Fundación Universitaria Los Libertadores que la policía excede sus prácticas de control de la manifestación. Asociado, consideran que los medios son parcializados pues no existe una verdadera libertad de prensa, la información que subyace en los medios responde a la inmediatez y no posee un análisis contundente y objetivo. Prima las opiniones sobre el tema político, mas no hay una reflexividad ni posicionamiento crítico.

En los dos debates parece que la familia desempeña un papel decisivo en la consolidación de un sujeto con valores y moral, lo que denominan cultura, la cual la asocian a una cultura política.

\section{Etnografía virtual.}

Tabla 1

Matriz de análisis ${ }^{10}$

\section{Pertinencia y solidez de los enunciados respecto de una situación/problema}

1.1. Se evidencia o no que los/las estudiantes analizan los planteamientos/ argumentaciones que sus compañeros/as exponen; o más bien reaccionan ante los mismos de forma reactiva y/o unilateral.

Se encuentra que las respuestas reactivas y/o unilaterales que buscarían anular un comentario son poco influyentes en las conversaciones revisadas, salvo casos concretos, se evidencia con claridad choques o confrontaciones entre puntos de vista, pero, es de resaltar que no son comunes al general de las conversaciones. A este respecto es necesario tener en cuenta que los comentarios escritos pueden ser borrados a discrecionalidad de cualquier persona; en efecto, se pueden "ocultar" o "reportar" para que sea borrado.

Sin embargo, es posible ver cómo a reiterados comentarios que se preocupan

\section{Perspectivas sobre una situación/ problema}

2.1. Las situaciones o conflictos son analizados; o simplemente se opina sobre los mismos.

Lo que se encuentra en la revisión y análisis de la información que han proveído los grupos tenidos en cuenta, hace referencia, en primer lugar, a que las comunicaciones expresadas son particularmente sintéticas, a veces apoyadas con imágenes preparadas que cuentan como texto (memes), por tal motivo, los ejercicios de argumentación de lo que se expresa, cuando los hay, apuntan a elementos contundentes que pretenden tocar al otro.

Por ejemplo, en una línea de comentarios relativos a si se iban o no a llevar a cabo clases debido a la situación que impuso el paro, puede verse cómo, de un comentario superficial, respecto de la no realización de clase: 


\section{Pertinencia y solidez de los enunciados respecto de una situación/problema}

exclusivamente por la realización o no de las clases, se responde con otros que pueden juzgarse reactivos, por ejemplo, a los comentarios:

"Buenas noches, me gustaría saber si la cancelación incluye cargas laborales, qué pasa con secretarias, monitores y demás personas"; "Buenas noches quisiera saber cual es el horario de los administrativos ya que mañana se vencen plazos y debo radicar unos documentos".

Se responde lo siguiente:

"Realmente hay ocasiones en las que siento algo muy cercano al asco por mucha de la gente que responde a esta clase de anuncios. No están estudiando? Su formación básica no les da para dar una respuesta lógica y argumentada si se sienten molestos? No tienen un mínimo de comprensión de lectura para no preguntar lo que es claro en el mensaje? Qué tristeza que este sea el futuro de la sociedad, ahora comprendo por que votan como votan y por que estamos cada vez más hundidos".

Se destacan de esta forma comentarios reactivos frente a las opiniones de los compañeros preocupados por la asistencia a las clases los días 28 y 29 de agosto del año 2013 , o por invitar a movilizarse y participar de las marchas. Incluso hay el uso de palabras insultantes como "babosos" o afirmaciones como "no ve más allá de sus narices", sin ningún tipo de análisis y de manera contestataria. Es evidente que este tipo de comentarios posteados en el muro, no tienen que ver con los problemas coyunturales del paro agrario y la percepción y vinculación que las y los estudiantes tendrían con este. Algunos ejemplos adicionales son:

"Hay que ver noticias por favor reaccionen"; "que cantidad de babosos, sino quieren estudiar, inscribanse a una pública, van a tirar piedra y no pierden el dinero, babosos"; "mire muchacito si no sabe de universidades publicas no hable y no es el hecho de no estudiar es el ver la situación del país, mire más haya de sus narices para haber si madura".

Por otro lado, no es posible hablar con alguna certeza significativa que los/las estudiantes analizan los planteamientos y

\section{Perspectivas sobre una situación/problema}

"cagada mañana si quería ir xd".

Surge el siguiente con un carácter más argumental:

"Pienso que no sólo no hay que no ir a clase por el hecho de que la Universidad lo diga, sino que no deberíamos ir como muestra de solidaridad al paro de nuestros campesinos".

Otro comentario con ese mismo carácter sería el siguiente:

"Es que acaso la universidad está como Santos... ¿no existe ningún PARO? (...) ¿dónde está la solidaridad con nuestras comunidades campesinas? no es el hecho de no QUERER asistir a las vías de hecho pacificas. Ellos por pertenecer a una entidad PRIVADA creen que no tienen la obligación moral de responder a este tipo de manifestaciones, se han preguntado acaso de donde sale la comida que a diario consumen?? que pasaría si nos uniéramos como pueblo?? esa es la educación que quieren impartir, diciendo simplemente si quiere ir bien sino pues también. (...) uested verá?? que tristeza reconocer que uno estudia en una universidad que no tiene en cuenta la crisis colectiva, la solidaridad, y sobre todo la conciencia social".

Vale resaltar que comentarios como el anterior pesa en el hilo conversacional si se tiene en cuenta el conteo de veces que alguien ha manifestado que "le gusta" lo que se ha sido expresado (185 veces para este caso).

Otra forma encontrada de argumentar un punto de vista se lleva a cabo mediante la apelación a videos u otros documentos, como fotografías, que pretenden dar peso a cierta postura en particular: (DENUNCIA PÚBLICA: ATRAPADOS EN TRANSMILENIO después de lo sucedido hoy... -video 2-).

Sin embargo, prevalecen/coexisten las respuestas afirmativas o que reafirman comentarios previos sin cuestionarlos o establecer un diálogo con los mismos. Por ejemplo, véase la siguiente cadena de comentarios en relación con la no realización de clases:

"Si no van los de la mañana yo como estudiante nocturno tampoco voy!!!! además es el final de la supercopa"; "mas bien deberian decir se reanudaran las

\section{Análisis de situaciones 0} problemas

3.1. La situación o problema es caracterizada, vista en sus múltiples aristas, así como la forma en que operan dichas dimensiones; o más bien prevalece una mirada superficial, incipiente, demagógica sobre los mismos.

Las conversaciones, como se ha venido exponiendo, han girado en torno a la cancelación o no de las clases en los días en los cuales el "paro agrario" tuvo su mayor algidez; la situación relativa al paro no gozó de un nivel mayor de análisis pues se acentúo el dejar a un lado la indiferencia respecto del mismo y sumarse a él ya que la situación del país así lo ameritaba:

"No somos alumnos ordinarios; somos alumnos especiales que estudiamos porque queremos salir a delante por nuestra cuenta y somos trabajadores también... pero eso no significa que a ustedes como entidad privada ni a nosotros como 'particulares' no nos deba interesar el acontecer social y los problemas de las otras esferas sociales!.. por el contrario, que se escuche nuestra voz de indignación".

Sin embargo, en algunas ocasiones muy puntuales se llega a dimensionar con mayor amplitud la situación. Ejemplo de ello, tenemos lo siguiente: un/a estudiante cita unas palabras de Jaime Garzón; "El problema de los colombianos es que no tenemos una conciencia colectiva. Tenemos una posición cómoda e individual ante la vida"; a los que algunos/as estudiantes contestan:

"Claro que no lo tenemos".

"Podríamos tenerlos pero las elecciones son muy rápidas nadie vota y los que tenemos conocimientos no podemos ingresar aun".

"No votamos por que no se dan a conocer las propuestas, seguimos con intereses individuales... hoy en día no se puede decir que no se nos da el espacio hay muchas maneras de divulgarlos, ademas de ser un derecho de nosotros como estudiantes. Por ejemplo en el paro campesino alguien leyó los artículos 64 y 55 de la constitución política, porque no nos amparamos en ella?..., nadie dijo que fuera fácil solo que valdría la pena".

Como se podrá ver, en algunos comentarios en el muro se observa un 


\section{Pertinencia y solidez de los enunciados respecto de una situación/problema}

argumentaciones que se exponen en los hilos conversacionales y que esto se refleje es las suyas propias, prima la consecución de opiniones, algunas más contundentes que otras, así como ciertas fracturas donde se controvierte el hilo de la conversación, pero sin que esto denote niveles mayores de análisis. A su vez en estos modelos de comunicación se puede pasar de un tema a otro sin que los comentarios, no obstante, sean consecutivos y parezcan relacionarse.

1.2. Cuando responden a un planteamiento lo hacen con una perspectiva argumentada y sólida; o prevalecen las afirmaciones contestatarias, unilaterales, irreflexivas y/o que anulan los matices/diferencias.

Como se ha propuesto, las conversaciones son en particular breves y concretas, de tal forma que estimar la solidez y argumentación en un universo como este requeriría de mayores referentes; no obstante, se identifican planteamientos que cuentan con un mayor peso argumentativo, ejemplo de ello serían los siguientes relacionados con la actitud apática que se

\section{Perspectivas sobre una situación/problema}

clases el lunes jiji”; "JAJAJAJA Vamos pensando en el futuro Ya jajajajajaa”.

Vale la pena resaltar una preocupación álgida de los estudiantes por la seguridad, por las manifestaciones, producto del paro, que se venían realizando en la ciudad y en zonas cercanas a la universidad. Parece sentían temor de asistir o, por el contrario, es una buena fachada para no ir a clases. Adicional a lo anterior hay una constante invitación por parte de los estudiantes a participar de las marchas y reconocer el "paro agrario". En este punto algunos estudiantes realizan varias invitaciones a participar del cacerolazo, indicando los puntos de encuentro para representar a la universidad. De igual manera intentan vincular a los otros miembros del grupo sensibilizando a través del nombre de la institución:

"Apoyen el paro la universidad no hará nada como siempre"; "lo mínimo que debieron hacer fue cancelar clases y tomar en cuenta que iba a ser muy complicado para mucha gente llegar a la Universidad y ni eso pudieron hacer. Apoyen o no el paro, es una pésima forma de gestionar la confianza que le damos cada semestre con los millones que se pagan (...)".

"Hoy 29 de agosto la marcha la realizaremos nosotros la comunidad libertadora: Marcha: Parque Nacional (entre las calle 36 a 39 y carreras séptima y quinta-) Lugar de encuentro: ECOPETROL".

2.2. Son reconocidas y respetadas las diferentes concepciones (ideologías) o perspectivas sobre una situación o problema; o son más bien desconocidas, anuladas, deslegitimadas.

Conforme el material revisado, no se encontraron como tales perspectivas ideológicas identificables y claramente discernibles; como el marco general de las discusiones se dio a la luz del "paro agrario" experimentado en Colombia, las principales posturas se dieron frente a la posición del Estado en cabeza del presidente (negando la existencia del paro mismo). Y de la institución universitaria (negándolo también pues contemplaba

\section{Análisis de situaciones 0} problemas

análisis más detallado de la situación. Sin embrago, la mayoría de post son de carácter superficial sin bases contundentes o sin solidez. Lo anterior no indica que algunos no vean las implicaciones que trae consigo el paro campesino.

" $Y$ de donde queda el apoyo a nuestros campesinos.......Esto es lo que nos quieren enseñar la indiferencia"; "parece que esos principios de los libertadores fueran fachada, la universidad no puede ser indiferente a la realidad social si los ideales vienen de de 3 protagonistas de la historia Colombiana”; “Cuántos Libertachos a favor del paro? Hay que despertar!".
3.2 La solución planteada, o la forma de asumir un problema, es propuesta desde una perspectiva reflexiva/comprensiva teniendo claras las consecuencias de las mismas; o, prima la inmediatez y la coyunturalidad de acciones específicas y reactivas.

Tanto como proponer soluciones al problema estructural que representó el "paro agrario", no se evidenciaron, de nuevo, la situación se sustenta en discutir su apoyo, así como en diversos llamados de atención a comprometerse con la coyuntura que vivió nuestro contexto. En ese orden de ideas, se invita, exhorta y hasta reclama no hacerse partícipes con el 


\section{Pertinencia y solidez de los enunciados respecto de una situación/problema}

generaliza en los/las estudiantes frente al "paro agrario" así como de la institución: "El nombre de los libertadores no lo reflejan, y mucho menos en la misión ("Formar integramente profesionales y ciudadanos críticos con amplio sentido de los social, ético, estético y politico") y la visión ni decir sobre ello ("uso de metodologías innovadoras adecuadas al contexto de la educación superior local, nacional e internacional, para contribuir al desarrollo de la sociedad Colombiana") ¿uds en qué están contribuyendo a Colombia como un dia de hoy? ESO QUEDO SOLO EN PALABRAS Y PARA DAR PUBLICIAD Y MARKETING".

Y también:

"1800: Bolivar, Caldas y Santander, próceres de una independencia.... 2014: Bolivar, Caldas y Santander: edificios de una entidad PRIVADA que solo ve una cifra en cada individuo y no conoce el significado de la expresión SENTIDO COMÚN, su intención es formar ciudadanos cuadriculados para que nunca más hallá un Bolivar, un Caldas o un Santander..."

Ahora bien, la poca reflexividad en los comentarios sí es tangible en parte de las conversaciones, cuando se resaltan hilos conversacionales unilaterales que apuntan a la falta de decisión de la institución sobre cancelar o no las clases:

"Que bueno... muy bueno que no hay clase"; "no esta mal ya que evitaron la ida de la mayoría de estudiantes por la noche y parece bien q a esa hora definan la situación de mañana"; "jajajaja no puedo creer esto. Que ridicules ddefinitivamente como es posible y cuando muchos se han arriesgado ahi si se les da por cuidar la seguridad e integrida.. el colmo!"; "eso debia hacer desde ayer......"; "para que lo hace ir a uno si ala final las cancelaron que falta de seriedad"; "como ellos llegan siempre en carro. Lastimosamente en esa universidad metimos la platica".

Una situación reiterada se presenta frente a los comunicados de la institución, pues muchos estudiantes están a la espera de confirmar su asistencia a clase, de allí que reaccionan ante la "lentitud de la información oficial" y la "falta de compromiso" por parte de la universidad ante una problemática nacional.

\section{Perspectivas sobre una situación/problema}

la normalidad académica en medio del mismo):

"No me parece la actitud que toma la universidad!!! frente a un problema tan serio como el $q$ estamos atravesando... será que no tienen ancestros nativos del сатро".

Otro/a estudiante señala:

"Es que acaso la universidad esta como santos... no existe ningún PARO...!... donde esta la solidaridad con nuestras comunidades campesinas... no es el hecho de no ir a clase es el hecho de no QUERER a las vias de hecho pacificas... ellos por pertenecer a una entidad PRIVADA creen que no tienen la obligación moral de responder a este tipo de manifestaciones".

En la mayoría de comentarios se ve un ánimo cordial y de respeto en las tres páginas por parte de los estudiantes frente a los comentarios en el muro de sus compañeros y compañeras. La actitud se vuelve reactiva en particular frente a los comentarios oficiales, pero entre las y los estudiantes se avisan de que no hay clase y casi siempre se aclara que los comentarios son con respeto.

Sin embargo, los/las estudiantes estuvieron en situación de asumir una u otra postura frente al tema sin encontrarse deslegitimación o anulación en términos polares salvo en casos muy puntuales; un ejemplo que cobró un tono intolerante fue el siguiente, no obstante, terminó por diluirse en la conversación misma:

Estudiante A: "Deje de ser descarado, ud lo único que no quiere es ir a clase, si no quiere ir a clase, no pagues Uni y ya" (...) "entonces no opine pendejadas, si no quiere asistir, no lo haga y ya".

Estudiante B: "Pero por que le afecta los comentarios de él... cada uno es libre de escribir lo que quiera sin que tontos como usted lo juzgue".

Estudiante A: "creo no entiendes español, pero bueno igual te lo repito, si se quiere opinar, opina cosas coherentes, como dije, si quiere ir a clase vaya, si no, pues no, por una persona que no valla no se va a acabar la $U, y$ no es que me afecte, es que ese comentario da para decir las cosas como son".

\section{Análisis de situaciones 0} problemas

paro; no ir a clase así hubiese normalidad académica, sería una forma ínfima, aunque inicial de respaldarlo. Esto, en medio de la diatriba que creó el posicionamiento de la institución frente a cancelar o no las jornadas académicas.

En esa medida se pueden encontrar comentarios que se limitan a esperar una confirmación institucional sobre el desarrollo de la jornada (mayoría), menos reflexivos y comprensivos de la situación general:

" $Y$ a los que no podemos nos repondrán las clases es lo mínimo que pueden hacer ya que por ustedes no entender las calamidades que se están presentando hoy y nos impiden asistir y por el 'profesionalismo' que tienen no pueden permitir que la mayoría de estudiantes se pierdan de notas o clases... espero que después no seamos los perjudicados por ustedes no pensar en la comunidad estudiantil... GRACIAS".

"Pero como pueden decir que el que asista bien y el que no también, por favor señores, lógico, lógico que van haber consecuencias, las fallas, el quedar atrasado en el tema que se ve, ¿les parece poco? les pido un poco de consideración con los que no pueden ir. ¿o es que van a reponerle el tema que se ve? Que pasa alma mate. DESPIERTA".

Junto con otros que problematizan la situación desde la perspectiva de la movilización social resaltando que la cuestión no es sencillamente de asistencia/ no-asistencia. Las consecuencias en ese sentido no se reducirían a una falla en los listados de asistencia pues lo que estaría en juego sería mucho más que eso:

"Están siendo ajenos a la realidad que se vive, comprometerse con nuestra formación profesional, también es unirse a las marchas, y evitar la basura que estamos viviendo".

Otros referentes serían los siguientes:

"Pues claro no ve dedonde hay pa comer agamos cuentas solo somos ficahas de su gran ajedrez"; "apoyemos a los campesinos., esto solo una de los tantos problemas que tiene el pais, como queremos ser profesionales si no tenemos un país $q$ respeta el bienestar de los mismos???? Les dejo la inquietud"; "un país se construye en las aulas no destruyendo la ciudad"; 


\section{Pertinencia y solidez de los enunciados respecto de una situación/problema}

Asimismo, en el grupo de Facebook, Memes los Libertadores, reaccionan con sus imágenes ante la falta de postura de la universidad por el paro agrario. Imágenes del presidente Santos ridiculizadas o de la imagen de la universidad, muestra la falta de contenido argumentado en sus formas comunes y estimadas positivas de expresarse, aunque exhibe con claridad una mirada inconforme frente a cómo actúa la universidad.

"Ya que el Petardo que tenemos como Presidente NO DA RESPUESTA a los campesinos, LOS LIBERTADORES nos pueden dar repuesta a los estudiantes???"; "pero la universidad es peor que Santos"; "seguro piensan como Santos que el paro no existe!!!".

\section{Perspectivas sobre una situación/problema}

En general, se daba aprobación al paro ya fuese por las implicaciones políticas del mismo o porque sencillamente significaba no ir a clases. Es de destacar también que en algunos casos se estaba inconforme con la decisión de no continuar con la normalidad académica; allí no se encontró una descalificación de dichas posturas, no obstante, se podía controvertirla o discutirla:

"Compañeros pensemos FULL es una entidad privada, a nosotros no nos subsidian la educación, con respecto a esto me surgen las siguientes preguntas: 1 . Se programan jornadas de recuperación de clase que por consecuencias del orden publico han sido canceladas? 2. En caso de que no se hagan nos reembolsaran el dinero de las horas de cátedra no vistas o serán abonadas en el recibo del siguiente semestre?. Estudiantes cuantos de nosotros no se ha metido en algún crédito para poder estudiar, cuanto nos hemos tenido que aplazar semestres, aunque el tema de la solidaridad con lo que sucede en nuestro pais también es nuestro dinero y nuestro progreso que se ve afectado. Quisiera conocer cuales son las propuestas de nuestros representantes al consejo académico con respecto a la situación que se presenta. Tenemos algún representantes al consejo académico con respecto a la situación que se presenta. Tenemos algún representante ante o perteneciente al MANE por parte de la universidad..."

Otro/a estudiante expresó:

"No estoy de acuerdo con la cancelación de la jornada académica... Esto es darle la razón a quienes quieren destruir el país... A demás nadie nos va a devolver la plata que pagamos de matrícula por las clases que perdamos... Esto nos perjudica... Tenemos derecho a estudiar...".

2.3. Son propuestas $y / o$ analizadas alternativas de solución a las situaciones o problemas que se discuten; o, la situación se queda en el nivel coyuntural y emotivo. Propuestas de solución a la situación estructural experimentada en las fechas tenidas en cuenta ("paro agrario") no son manifestadas en las conversaciones

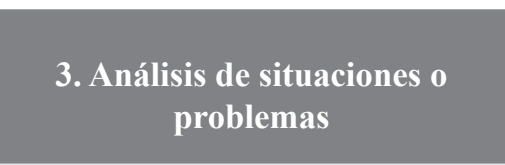

"¿dónde esta la solidaridad con nuestras comunidades campesinas? No es el hecho de no ir a clase, es el hecho de no QUERER asistir a las vías de hecho pacificas. Ellos por pertenecer a una entidad PRIVADA creen que no tienen la obligación moral de responder a este tipo de manifestaciones, se han preguntado acaso de donde sale a diario la comida que consumen?? Que pasaría si nos uniéramos como pueblo?? Esa es la educación que quieren impartir, diciendo simplemente si quiere ir bien $y$ si no pues también"; "usted vera?? Que tristeza reconocer que uno estudia en una universidad que no tiene en cuenta la crisis colectiva, la solidaridad, y sobre todo la conciencia social"; "piensan en vez de sensibilizarse con el país y decir apoyamos el parooooo porq somos colombianos y nos afecta en esa mismas protesta están los campesinos, EDUCADORES, médicos, TRANSPORTE PUBLICO y demás tomen conciencia por un mejor mañana es momento de hacerse sentir Colombia no es un poco somos todos asi que hagamos valer los derechos de todos no solo es el dinero". 
1. Pertinencia y solidez de los enunciados respecto de una situación/problema

\section{Perspectivas sobre una situación/problema}

3. Análisis de situaciones o problemas

revisadas; la magnitud del fenómeno y su complejidad pueden ser un claro impedimento para proponer ese nivel en los comentarios expuestos. En cuanto a la situación sobre ir o no a clases dependiendo de una determinación institucional, tanto desde la argumentación de elementos políticos hasta la intención simple de no tener clase, se soluciona en la inmensa mayoría de los casos proponiendo la no asistencia.

Se aboga entonces por la movilización social como acción alternativa a llevar a cabo en medio de la coyuntura; claro está, esto no implica que los/las estudiantes que no asistieron a clase lo hayan hecho porque se unieron a las actividades convocadas, sino simplemente por evitar las clases. Así lo indican los/las estudiantes:

"Todos debemos comprometernos a no ir a clase hoy, por tan solo dos que vayan sacan nota y toman asistencia. Vamos a apoyar el paro el paro nacional $y$ agrario. Por una Colombia mejor y menos corrupción".

"APOYEMOSELPARO, posición de la $U$, ..... ¿Las humanidades? Este país merece que existan verdaderas soluciones al AGRO, a la SALUD, a la EDUCACION, el EMPLEO INFORMAL".

"Mañana yo también me pongo la ruana y salgo a marchar".

"1. Dejen de lamentarse 2. Infórmese. 3. Apoyen las marchas".

Se evidencia entonces que las situaciones problemas son fundamentalmente mediáticas y emotivas, no existen propuestas concretas de solución o mejora de la situación. Eso sí, hay una relación contextual con las emisiones del gobierno, sobre todo con la polémica declaración de Juan Manuel Santos: "el paro agrario no existe", que permitió manipular la información y girarla sobre este hecho.

"Nunca les ha interesado la situación del pais les quedó grande el nombre "los libertadores",; "que falta de solidaridad con el pueblo Colombiano, si todos seguimos actuando como si no estuviera pasando nada"; "el tal para agrario OBVIO QUE SIII EXISTE unilibertadores, 


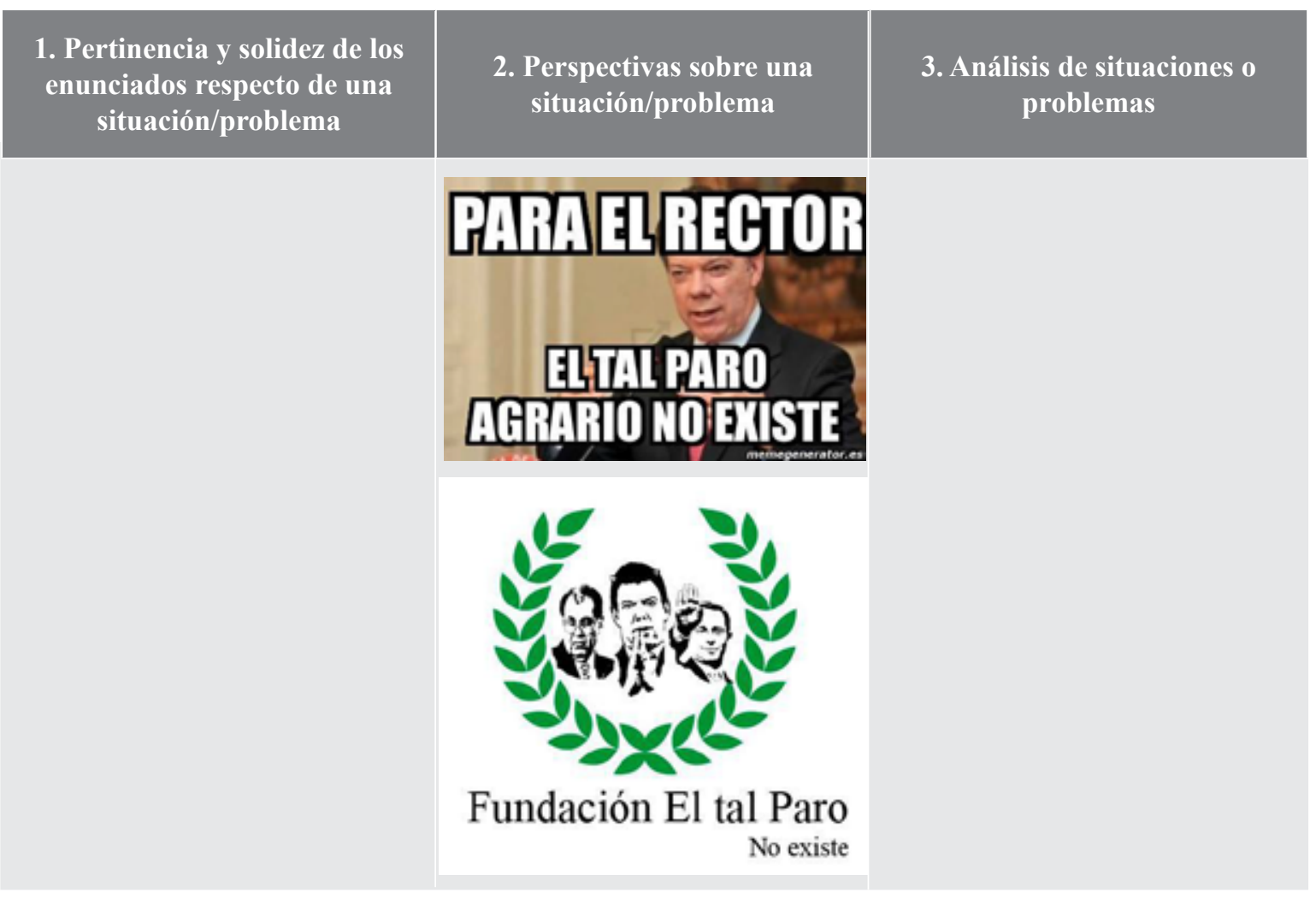

Fuente: elaboración propia.

En este contexto, los estudiantes han adquirido algunos conocimientos y prácticas para ejercer la ciudadanía. Sin embargo, aún hay un desconocimiento frente a los derechos y deberes consignados en la Constitución Política de Colombia, pues existe una influencia negativa de los medios de comunicación en el reconocimiento del conflicto interino y una oquedad en lo que respecta a nuevas manifestaciones políticas, sobre todo desde las propuestas de las y los excluidos. Las y los jóvenes consideran en algunos de los casos que la lucha por los derechos campesinos, de género, de raza, entre otros, son espacios para el vandalismo, que no tiene ninguna validez, igual que la consolidación de nuevos partidos políticos defensores de los derechos de los excluidos, debido a lo que observan en los medios de comunicación masiva.

La educación en referencia a las competencias ciudadanas está relacionada más con el civismo; a pesar de que este no debería ser el único referente, se vuelve casi que el ineludible producto de la apatía de las y los jóvenes y del mediatismo. Puede pensarse que si bien en el discurso de las y los estudiantes se encuentran debilidades que habrían de haberse subsanado en momentos previos de la formación (como por ejemplo el funcionamiento de Colombia en tanto República, el significado, sentido y estructura de un modelo democrático de gobierno, entre otros), ellas y ellos destacan lo superfluo y discursivo de este tipo de tópicos; se resalta entonces, por un lado, que las actitudes y conocimientos de corte cívico/civilista no alcanzan a acercarse a las dinámicas y situaciones que la ciudadanía, en un sentido no exclusivamente cívico y más político, implica; por el otro, que acentuar el abordaje y evaluación de las competencias ciudadanas solo por esta vía, sin ir un poco más allá en el entramado y contexto nacional, repercute acentuando la actitud pasiva y desinteresa de las y los estudiantes. Al parecer, hablar de ciudadanía sin referentes concretos 
que la problematicen, sin "tocar" y vincular a las y los ciudadanos, desmotiva y desvincula aún más a esas y esos jóvenes que se suelen signar como apolíticos, individualistas y desinteresados de la cosa pública.

La apuesta de formación en competencias ciudadanas, basada en el modelo de Jürgen Habermas, se desdibuja, pues a pesar de estar inmersos en un modelo económico globalizado, donde las fronteras se rompen, donde la economía no es local, sino que le juega a lo global, el sujeto se ha individualizado, no existe un arraigo cultural ni territorial. Al ser ciudadanos del mundo - capitalista/consumista/ global- ${ }^{11}$, pareciera que la identidad nacional ya no existe, la falta de interés por lo propio y por lo que sucede con los suyos está en incremento ${ }^{12}$. Ese nexo mínimo societal, el bienestar general, es cuando menos una referencia nostálgica; el carácter más puramente político de la ciudadanía ha quedado reducido a la figura del electorado:

La decisión de voto sólo influye, por lo común, en el reclutamiento de la clase dirigente $\mathrm{y}$, en lo que a sus motivos se refiere, cae fuera del alcance de la formación discursiva de la voluntad colectiva. Todo lo cual tiene como consecuencia una neutralización de las posibilidades de participación política abiertas jurídicamente con la institucionalización del papel del ciudadano (Habermas, 1992, p. 490).

A pesar de las postulaciones en el papel de una educaciónque forme ciudadanos conscientes de sus derechos y deberes y de su participación en la vida política, no se ejerce de esa manera. La ciudadanía con una significancia primigenia solo aparece en el momento de participar mediante el voto, sirviendo a los intereses de unos pocos, primando el clientelismo.

Se hace necesario que ese rol activo del ciudadano cuente con una base más fuerte que permita su dinamización, que lo lleve más allá de su enunciación jurídica: una cultura política propiamente dicha. Para Habermas (1998), se requiere del "esfuerzo cooperativo de una praxis ciudadana a la que nadie puede verse obligado por la presión de las normas jurídicas" (p. 9). Debe entonces contarse con el consentimiento, la motivación y la convicción en los ciudadanos que lo que guía su actuar político es el bien común, o como dice el autor que exista una "población habituada a la libertad política y acostumbrada a la perspectiva del 'nosotros' propia de las prácticas autogestionarias" (p. 9).

En ese orden de ideas, las acciones colectivas y los movimientos sociales han buscado la participación, en especial de las y los jóvenes, en su actuar por la lucha de derechos y la búsqueda del reconocimiento de las y los excluidos, los movimientos ambientalistas, antitaurinos, de homosexuales, entre otros, han mostrado la relevancia de conocer los derechos y los deberes y participar activamente en la política. Pues si bien, estos movimientos se gestan en el marco de una ausencia de representación en las instituciones estatales, invitan a la participación más activa para evitar que ese modelo perdure.

Las nuevas consolidaciones de ciudadanía hacen una invitación a que se evalué y reconceptualice el modelo de competencias ciudadanas desde lo educativo, fomentando el conocimiento y reconocimiento de los actuales movimientos sociales y las acciones colectivas, pluralizando el concepto de ciudadano, pues a pesar de estar en una dinámica globalizada y neoliberal, en un mundo altamente tecnológico y digitalizado, el ciudadano se sigue construyendo sin responder a parámetros, cada sujeto construye su propia ciudadanía, producto de la composición de los diferentes tipos de ciudadano y de acuerdo a lo que su contexto le indique.

La ciudadanía no puede verse como una realidad estática y definitiva, pues las y los sujetos están en un continuo proceso de construcción y deconstrucción de lo que puede llegar a ser un ciudadano -ya sea desde la más completa apatía o su contrario-; en ese sentido, más 
que asumir un ciudadano liberal, global, digital, cosmopolita, entre otros, es necesario ver el término en su dinámica real, compleja y viva, destacando que partir de una sola teorización negando lo anterior es, además de formalista, reduccionista para la formación de un sujeto verdaderamente activo políticamente.

El mundo globalizado que experimenta la individualidad del rol político de los ciudadanos, que se orienta por los intereses particulares de tendencia egoísta, es un hecho que los defensores del liberalismo no pueden seguir omitiendo, pues el agrietamiento de las estructuras de los partidos políticos y la cadencia progresiva en las vías formales de participación que sostienen el modelo así lo indican.

También es de relevancia la influencia de los medios masivos de comunicación pues sus estrategias comunicativas -Facebook, en el diario o la prensa- se dirigen hacia los deseos y los afectos de los espectadores, haciendo que se vinculen y guarden fidelidad a ciertos grupos o famepage o a ciertos presupuestos informativos. Esto sucede en relación con el valor simbólico que pueda tener, pues las y los jóvenes necesitan apropiarse de alguna información y hacer uso de ella para tener un rol de importancia dentro de su entorno social.

Estos medios tienden a modular todas las actuaciones de los sujetos, incluso sus prácticas políticas, pues incitan a adoptar unas formas de pasividad o mediatez, de comunicarse, de hablar. Este rol del sujeto interpelado por las pantallas hace que la noción, por los contextos, se aproxime más a la de comunidad.

\section{Conclusiones}

Las competencias ciudadanas se han enarbolado con base en necesidades concretas y claramente plausibles en nuestro contexto; $\sin$ embargo, el énfasis que ponen en un conjunto de "actitudes para actuar en la sociedad", y en conocimientos básicos del sistema político democrático, definitivamente minimizan y hasta marginalizan el sentido mismo de la ciudadanía como agencia política por excelencia. Parece que el componente político de la ciudadanía se ha menguado tácitamente sin contar que es ciego a los conflictos que implican sus significados tanto en el entorno académico como en el político.

La ciudadanía se nos muestra mediante las competencias ciudadanas, como una actitud socialmente deseada de llevarse en sociedad, en el marco de una democracia que se supone funciona adecuadamente (hipotéticamente o en teoría). Claro ejemplo de lo anterior es el énfasis que ponen en la comprensión de la Constitución política y sus fundamentos, los derechos y deberes que consagra y la organización de la estructura estatal (Universidad Nacional de Colombia, 2012).

Por ende, la evaluación en competencias ciudadanas no refleja (legítima) las formas de vinculación no constitucionales (vía voto) de relacionarse con el Estado; es por eso que el Estado para muchos es una figura ausente, distante, fortaleciendo la pasividad de los sujetos frente a la realidad política de una sociedad.

Los cuestionamientos anteriores no quieren decir que las competencias ciudadanas son inútiles o que deben erradicarse del entorno escolar y universitario; quieren alertar acerca de un tratamiento de la política en la sociedad que se queda en algo así como el "buen pensar y buen actuar", como si el papel político de un ciudadano/ciudadana fuese solamente una cuestión actitudinal ${ }^{13}$.

Las competencias ciudadanas podrían partir de una concepción más arraigada en el fortalecimiento de la cultura política como tal, más que en el civismo como forma de actuar políticamente correcta ${ }^{14}$, de esta manera, podrían hacer frente a los problemas derivados de la figura del ciudadano-cliente y del privatismo 
cívico. La autodeterminación de las y los ciudadanos es fundamental y no debe desestimarse en pro de la convivencia pacífica, debe ser parte fundante de aquella.

El ciudadano no es solo aquel respetuoso de la ley y de los demás, conocedor de las formas establecidas de participación política, es, juicio particular, un agente activo, libre y dinámico en la vida política de una sociedad; VallarinoBracho (2002), examinando las ideas de Arendt al respecto, provee una perspectiva acorde a la nuestra en cuanto al ciudadano, "es un hombre [y una mujer] que participa activamente en el mantenimiento de los asuntos humanos, un codirigente de la ciudad" (pp. 1-2). Al igual que

[...] es el hombre [y la mujer] que deja el dominio privado para ejercer la libertad política con sus semejantes, que intenta con sus pares de fundar un nuevo gobierno que ha de representar el conjunto de los ciudadanos y cuya legitimidad proviene de los cuerpos políticos subalternos (p. 9).

Muchos de los movimientos sociales que influyen en la sociedad contemporánea y que ya cuentan con una no despreciable tradición política ${ }^{15}$, los renovados actores que les dan vida, están dando una voz de alerta sobre la participación de las y los ciudadanos en la sociedad, cuestionan en el hacer político del diario vivir el concepto que se ha asumido como estático y general de la sociedad; llevan a la práctica formas de acción política novedosas y convocantes que en las competencias ciudadanas no son tenidas en cuenta; es más, pareciese que al omitirlas las desestima y deja al ostracismo.

Las dinámicas actuales permiten que el sujeto mute, que esté en constante subjetivación, como su rol de ciudadano. Las sociedades contemporáneas han impreso un rol mercantilista que hace que se adopten lenguajes, formas de vida, emotividades, géneros, nuevas formas de ver y de exhibir en cuerpo. Estos factores son de incidencia en lo que se considera "ciudadano" y por ende relevantes en la evaluación estatal.
Un elemento en términos metodológicos a destacar es el siguiente: en espacios como Facebook resultan posibilidades de gran interés para llevar a cabo indagaciones novedosas en las cuales, así no sean concebidas como fuentes formales/legítimas de información para ciertos sectores de la academia, sí permiten acercarse a la realidad desde una perspectiva acorde a las dinámicas actuales; su riqueza, ausencia de límites concretos, la posibilidad de dejar expresar la espontaneidad y la libertad sin mayores restricciones, viabiliza el hacerse con interesantes formas en las que son abordadas diversas problemáticas que en la formalidad de una entrevista o interpelación directa suelen minimizarse o sencillamente omitirse.

Así mismo, es un espacio donde la creatividad cobra fuerza dejando ver a su vez expresiones particulares de los y las personas en tanto sujetos; es claro que en estos momentos las redes sociales son uno de los contextos centrales en donde se expresa y construye el sujeto, no puede entonces ser relegadas a simple divertimento o cuestión de pasatiempo. Adicionalmente, las redes sociales como Facebook permiten producir información de diversas formas que no se limitan al texto escrito, dando paso a los gráficos y el video, así como de complementarlos y ponerlos en articulación.

Otras conclusiones que encontramos relevantes presentar son las siguientes:

a. Los derechos de las personas, no obstante, su existencia en el lenguaje estatal institucional, así como su validación en el escenario político, en muchos casos, situaciones y en el cuerpo de varias poblaciones, no se cumplen; es necesario problematizar por qué no se cumplen. La democracia tiende a gozar de un carácter nominal, los derechos promulgados no son garantizados ni es fácil hacerlos defender por sí mismo.

b. Conocer en teoría lo que significa un modelo de gobierno democrático no implica vis a vis que la democracia 
opere en la práctica. Lo mismo sucede para el caso de las leyes y normas. Sin embargo, existe también la percepción que por tener ese nivel de legitimidad fuera una realidad práctica; se hace entonces importante cuestionar esas normas y leyes del sistema, pues conocerlas implica comprenderlas y apropiárselas críticamente.

c. Elmiedoylatensión son dos sensaciones presentes a la hora de tocar el tema político, del Estado, de la inequidad social, a la hora de plantear una posición diferente y peor inconforme, entre otros; esto se evidencia en las charlas, en las respuestas de la encuesta y hasta en espacios como Facebook. Es más importante proteger la seguridad personal que exponerse.

d. Los medios de comunicación tienden a manipular la información (la libertad de prensa no existe), a hacer un manejo diestro frente a ciertas problemáticas de la sociedad. Paralelamente, espacios como Facebook permiten vehiculizar opciones alternativas para la comprensión de dichas realidades, hacen las veces de una especie de punto de fuga por el cual movilizar lo que se suele considerar como políticamente incorrecto.

e. Las redes sociales son espacios de potenciación y deliberación fuertes, una especie de mecanismo de presión en los que al menos el derecho a la expresión no está tan opacado, pero, se tiende a dar credibilidad y efectividad a formas tradicionales de posicionarse como las marchas o las movilizaciones sociales, que en últimas son las que se juzgan como realmente efectivas.

f. Las cuestiones ciudadanas, la participación de los ciudadanos, los momentos de convocatoria y preocupación general, son poco asumidos por la falta de tiempo e interés de las personas.

g. Prima la participación no formal, la que no compromete directamente, de tal forma que el reconocimiento de los espacios formales de participación es poco valorado así se juzguen más efectivos.

h. Organizarse como ciudadanos en torno a un tema o problemática es visto como algo lejano, difícil y hasta peligroso.

i. Uno de los principales motivos para que surja ese diluido interés general es el rechazo a políticas gubernamentales juzgadas inadecuadas.

j. La ciudadanía es un título que otorga el Estado, así como los derechos y los deberes, el Estado es quien reconoce esos elementos; el ciudadano no haría cuerpo de ellos, no les daría vida materializándolos, vienen de una esfera exterior a ellos. Existe también la idea de que ejercer la ciudadanía no se reduce al voto, no obstante, se observa que ser activo políticamente implica primero observar y respetar las leyes y a los demás, así como operar mediante lo que se considera como estipulado en materia de participación. La ciudadanía se considera como algo fundamentalmente individual. El Estado cumple un papel ambiguo, promulga los derechos y vela por su cumplimiento mientras los transgrede, figura como indiferente y manipulador.

k. Existe la claridad en cuanto a que ciudadanía y civismo son cosas diferentes. A manera de reflexión, se piensa que la ciudadanía debería asumirse en espacios comunes y situaciones cotidianas.

1. La ciudadanía en la actualidad se encuentra fuertemente afectada por las dinámicas económicas y la globalización, más allá de una actitud cívica se requeriría preocuparse por el bienestar general o el no cumplimiento de los derechos. Estos factores favorecen la indiferencia, el desinterés, la pasividad y la inercia frente al accionar estatal. 
m. Las redes sociales y similares no profundizan en el tratamiento de la información, son mediáticas, responden a la necesidad del consumo o participación, es decir, la información siempre está vehiculada a través de sentimientos/afectos, lo que busca mayor participación.

n. Las personas suelen sumarse a puntos de vista sin cuestionar la fuente, se toma partido acríticamente, por tal motivo no hay mayores análisis. Urge entones comenzar a cuestionarse sobre el rol que como ciudadanos se han venido desarrollando, ya que existen poderosas prácticas como el clientelismo y la corrupción que dificultan aún más dejar el rol acrítico ya señalado. La "ignorancia" y falta de educación son también expuestos como determinantes de esta situación.

o. La familia es un ambiente en el cual se puede formar ciudadanos; no obstante, y al parecer, ella está perpetuando valores como el individualismo, el consumismo, la apatía y otras valoraciones tales como la desconfianza en las instituciones por su corrupción.

p. Hay una preocupación por los problemas de la sociedad, pero esta preocupación no trasciende en acciones o posicionamientos más contundentes que un punto de vista.

q. Lo político se hace próximo cuando es cercano, cuando afecta directamente al individuo a la manera de "si no es conmigo no me preocupa".

r. A las y los estudiantes les gustaría participar en la movilización social, sin embargo, prácticas como las marchas suelen derivar en vandalismo, violencia e inseguridad, motivos por los cuales no se participa. Otras vías posibles no son claras o "seguras", de allí que exista cierto sentimiento de impotencia. s. Las nociones de que las movilizaciones generan vandalismo, violencia o inseguridad, provienen de lo que se escucha y ve en los medios de comunicación y en internet, así mismo lo que su familia inculca, manifestando un control no físico, sino del actuar.

t. Las personas que se encuentran en situaciones de vulneración de sus derechos parecieran no preocuparse por su situación, "no se ayudan". La cuestión es una lucha individual por salir adelante, buena parte de los que están mal es porque así lo quieren; no hay que esperar a que el gobierno dé soluciones.

u. En tanto los ciudadanos son los que han elegido las personas que conforman el gobierno, todos son finalmente corruptos y antes que nada conformistas, se tiende a naturalizar la violación de los derechos y otros problemas similares.

\section{Notas}

1 "Entidad especializada en ofrecer servicios de evaluación de la educación en todos sus niveles, y en particular apoyar al Ministerio de Educación Nacional en la realización de los exámenes de Estado y en adelantar investigaciones sobre los factores que inciden en la calidad educativa, para ofrecer información pertinente y oportuna para contribuir al mejoramiento de la calidad de la educación" (ICFES, 2016).

${ }^{2}$ Las luchas contra el poder afirman el hecho de ser diferente, fortaleciendo todo lo que lleva al individuo ser individuo. En ese sentido, lo que plantea Michel Foucault (1975), es que cada vez que las personas luchan por sus derechos se oponen a determinadas formas de gobierno, afirmando una subjetividad diferente a aquella que se les quiere imponer, un proceso de construcción y transformación de sí mismo. 
${ }^{3}$ El interés cognoscitivo emancipatorio es entendido por J. Habermas (1982) de la siguiente forma: "Mientras que el interés cognoscitivo práctico y el interés cognoscitivo técnico tienen sus bases en estructuras de acción y experiencia profundas (¿invariables?) y están vinculados a los elementos constitutivos de los sistemas sociales, el interés cognoscitivo emancipatorio posee un estatuto derivado. Asegura la conexión del saber teórico con una práctica vivida, es decir, con un 'dominio objetual' que no aparece sino bajo las condiciones de una comunicación sistemáticamente deformada y de una represión sólo legitimada en apariencia" (pp. 324-325).

${ }^{4}$ La web 2.0 se le llama a la segunda generación de esta, generalmente se asocia al concepto de redes sociales, donde existen mayores ejercicios de participación pues producen y comparten contenidos de diversa índole, es aquí más evidente la experiencia interactiva.

5 "El público y la opinión serían el objeto ubicado en el centro de los dispositivos de seguridad, que intentarían a través del "medio ambiente" reducir el campo de lo posible" (Lazzarato, 2006b, p. 12).

${ }^{6} \mathrm{El}$ paro nacional agrario/campesino fue una movilización a escala nacional que convocó en particular a los pequeños campesinos, cultivadores de papa y cebolla de Boyacá, en un principio, y productores del sector agropecuario colombiano (otros sectores y grupos se le fueron sumando progresivamente como los del gremio de los transportadores y otros sindicatos); se convocó ante los medios el 19 de agosto de 2013 y se extendió en sus negociaciones hasta el 7 de septiembre de 2013. Los móviles del mismo corresponden a la precaria situación de estos agricultores, debido al rol de desventaja en la economía nacional, pues el modelo económico existente los sumió en la quiebra.

${ }^{7}$ Tampoco se ha podido establecer características de los y las estudiantes como la edad, si solamente estudian o estudian y trabajan $u$ otros elementos socioeconómicos y socioculturales.

${ }^{8}$ Este es un documental que muestra las luchas de los familiares por el reconocimiento, la justicia y la reparación de ellos y miles de desaparecidos víctimas de la violencia. La apuesta periodística mostraba cómo era visto el conflicto y en especial este tema desde la postura estatal y la de diversas organizaciones que luchan por los Derechos Humanos. En consecuencia, era evidente que las estadísticas estatales no dimensionaban el verdadero panorama. En el año 2010 la noticia del hallazgo de una fosa gigantesca en el cementerio del pequeño municipio de La Macarena, en el Meta; en donde se dijo que estarían hasta 1.000 cadáveres N.N., descuartizados y cuerpos que evidenciaban el paso de la violencia, un número de sujetos sin reconocer más vasto que las víctimas de las dictaduras del Cono Sur.

9 Este documental de Jorge Furtado (1989) muestra la situación que experimenta una población en franca situación de exclusión y vulneración social en el contexto latinoamericano, se centra en el problema del hambre y la injusticia social para cuestionarse sobre la libertad de las personas a la luz de condiciones de vida completamente infrahumanas; cuestiona la primacía de la lógica del mercado, así como el total quietismo del Estado y de las y los ciudadanos frente al problema.

${ }^{10}$ A la hora de transcribir los comentarios expuestos en las conversaciones de los grupos se ha mantenido la fidelidad al original; no se han realizado correcciones o ajustes en materia de redacción y ortografía.

${ }^{11}$ Destáquese además la actual exacerbación de nacionalismos y regionalismos en varias latitudes del globo, que muestran otra faceta de las posibles reacciones a la globalización y homogeneización cultural.

${ }^{12}$ Esta situación se conecta con el fenómeno expuesto por Habermas denominado la 
juridización de la vida: “[...] tendencia que se observa en las sociedades modernas a un aumento del derecho escrito. En esta tendencia podemos distinguir entre la extensión del derecho, es decir, la regulación jurídica de nuevos asuntos sociales regulados hasta el momento de manera informal, y el adensamiento del derecho, es decir, la desmenuzación de una materia jurídica global en varias materias particulares" (Habermas, 1992, p. 504).

${ }^{13}$ Actitudes concernientes, por ejemplo, examinar argumentos, analizar situaciones de conflicto, caracterizar y contrastar las dimensiones que hacen parte de una situación, de un problema o de su solución, entre otras (Universidad Nacional de Colombia, 2012).

${ }^{14}$ Una ciudadanía tenue en cuanto a formación y cultura política puede derivar en la figura que H. Arendt (2004) denominó como "populacho", especialmente proclive al autoritarismo: "Mientras el pueblo en todas las grandes revoluciones lucha por una verdadera representación, el populacho siempre gritará en favor del 'hombre fuerte', del 'gran líder'. Porque el populacho odia a la sociedad de la que está excluido tanto como al parlamento en el que no está representado" (p. 162). Y continúa: "el populacho se inclina necesariamente hacia la acción extraparlamentaria. Además, se muestra proclive a buscar las verdaderas fuerzas de la vida política en aquellos movimientos e influencias que permanecen ocultos a la vista y que actúan tras bastidores" (p. 164).

15 Véase por ejemplo la propuesta de Ruth Lister (2004) en torno al debate sobre la regenerización de la ciudadanía, dándole cabida a una ciudadanía pluralista sintetizando el dilema tradicional de igualdad vs. diferencia.

\section{Referencias}

Ardèvol, E., Estalella, A., \& Domínguez, D. (2008). La mediación tecnológica en la práctica etnográfica. España: ANKULEGI.
Ardèvol, E., \& Pinyol, E. (s.f.). La domesticación de Internet. Recuperado de http://photographicsocialvision.org/domestic/pdf/elisenda_ardevol_y_eva_pinyol_cast.pdf

Arendt, H. (2004). Los origenes del totalitarismo. México: Taurus-Santillana.

Bonilla, E., \& Rodríguez, P. (2000). Más allá del dilema de los métodos. La investigación en ciencias sociales. Bogotá: Grupo Editorial Norma; Universidad de los Andes.

Chaux, E., Lleras, E., \& Velásquez, A. (2004). Competencias ciudadanas: de los estándares al aula. Bogotá: Uniandes; Ministerio de Educación.

Cortina, A. (1997). Ciudadanos del mundo. Hacia una teoría de la ciudadanía. Madrid: Alianza.

Del Re, A. (2001). Para una redefinición del concepto de ciudadanía. Memoria Académica. 9-10, 189-200. Recuperado de http://www.memoria.fahce.unlp.edu. ar/art_revistas/pr.2944/pr.2944.pdf

Delgado, R. (2003). Interrogantes en torno a la formación de las competencias ciudadanas y la construcción de lo público. En C. Yori (Ed.), Espacio público y formación de ciudadanía (pp. 115-134). Bogotá: Pontificia Universidad Javeriana.

Foucault, M. (1975). Vigilar y castigar. Buenos Aires: Siglo XXI.

Furtado, J. (Director) (2009). La isla de las flores. [Cortometraje]. Brasil. Autor.

García, N. (1995). Consumidores y ciudadanos. Conflictos multiculturales de la globalización. México D. F.: Grijalbo.

Gonzálvez, V. (2011). Educación para la ciudadanía democrática en la cultura digital. Comunicar, 18(36), 131-139. 
Habermas, J. (1982). Conocimiento e interés. Madrid: Taurus.

Habermas, J. (1992). Teoría de la acción comunicativa. Crítica de la razón funcionalista (Tomo II). Madrid: Taurus-Santillana.

Habermas, J. (1998). Ciudadanía e identidad nacional. Reflexiones sobre el futuro europeo. En, Facticidad y validez (pp. 619-643). Madrid: Trotta. Recuperado de http://www. proyectos.cchs.csic.es/politicas-migratorias/ sites/proyectos.cchs.csic.es.politicas-migratorias/files/Ciudadania_e_identidad_nacional - Traduccion.pdf

Hine, C. (2004). Etnografia virtual. Barcelona: UOC.

Horrach, J. (2009). Sobre el concepto de ciudadanía: historia y modelos. Revista Factótum de Filosofía, 6, 1-22. Recuperado de http://www.revistafactotum.com/ revista/f_6/articulos/Factotum_6_1_JA_ Horrach.pdf

Instituto Colombiano para la Evaluación de la Educación -[ICFES]. (2016). Quiénes somos. Recuperado de http://www.icfes. gov.co/quienes-somos

Lazzarato, M. (2006a). Por una política menor. Acontecimiento y politica en las sociedades de control. Madrid: Traficantes de Sueños.

Lazzarato, M. (Ed.) (2006b). El concepto de vida y de vivo en las sociedades de control. En Politicas del acontecimiento (pp. 25-48). Buenos Aires: Tinta y Limón.

Lazzarato, M. (2008). Postfacio. En G. Raunig (Ed.), Mil máquinas. Breve filosofia de las máquinas como movimiento social (pp. 109-118). Madrid: Traficantes de Sueños.

Lister, R. (2004). Ciudadanía y género. En E. Amenta, K. Nash \& A. Scott (Eds.), The
Wiley-Blackwell Companion to Political Sociology (pp. 79-93). Oxford: Blackwell Publishing.

Mejía, A., \& Perafán, B. (2006). Para acercarse al dragón, para amansarlo, es necesario haberlo amansado primero: una mirada crítica a las competencias ciudadanas. Revista de Estudios Sociales, 23, 23-35. Recuperado de http://res.uniandes.edu. co/view.php/323/view.php

Morley, D. (2008). Medios, modernidad y tecnología. Barcelona: Gedisa.

Morris, H. (2010). "Cuántos son los desaparecidos en el país"(Capítulo243). Contravía. [Documental]. Colombia: Canal Capital. Recuperado de: https://www.youtube. $\mathrm{com} /$ watch? $\mathrm{v}=\mathrm{UdbqG} 35 \mathrm{H} 6 \mathrm{Ho}$

Nussbaum, M. (1999). Patriotismo y cosmopolitismo. En Los límites del patriotismo. Identidad, pertenencia y ciudadanía mundial (pp. 68-125). Buenos Aires: Paidós.

Rodríguez, A., Ruiz, S., \& Guerra, Y. (2007). Competencias ciudadanas aplicadas a la educación en Colombia. Educación $y$ Desarrollo Social, 1(1), 140-157. Recuperado de http://www.umng.edu.co/ documents/63968/80132/RevNo1 voll. Art10.pdf

Savransky, M. (2011). Ciudadanía, violencia epistémica y subjetividad. Revista CIDOB d'afers internacionals, 95, 113-123.

Thiebaut, C. (1998). La vindicación del ciudadano. Un sujeto reflexivo en una sociedad compleja. Barcelona: Paidós.

Universidad Nacional de Colombia (2012). Así serán las pruebas saber pro. Orientaciones para los programas curriculares de la Universidad Nacional de Colombia que 
serán evaluados el próximo 3 de junio. Bogotá: Dirección Nacional de Pregrados. Recuperado de http://www.unal.edu. co/diracad/formatos/2012/Asi_seran las_pruebas_SABER_PRO_2012-1.pdf

Vallarino-Bracho, C. (2002). Ciudadanía y representación en el pensamiento político de Hannah Arendt. Cuestiones Políticas, 28, 11-29. Recuperado de http://www. cholonautas.edu.pe/modulo/upload/ Vallarino.pdf 
